\title{
BMJ Open Is loneliness associated with increased health and social care utilisation in the oldest old? Findings from a population- based longitudinal study
}

\author{
Hanyuying Wang, ${ }^{\odot 1}$ Emily Zhao, ${ }^{1}$ Jane Fleming, ${ }^{\odot 1,2}$ Tom Dening, ${ }^{\odot 3}$ \\ Kay-Tee Khaw, ${ }^{2}$ Carol Brayne, ${ }^{1,2}$ on behalf of the CC75C study collaboration
}

To cite: Wang $\mathrm{H}$, Zhao E, Fleming J, et al. Is loneliness associated with increased health and social care utilisation in the oldest old? Findings from a population-based longitudinal study. BMJ Open 2019;9:e024645. doi:10.1136/ bmjopen-2018-024645

- Prepublication history and additional material for this paper are available online. To view these files, please visit the journal online (http://dx.doi. org/10.1136/bmjopen-2018024645).

Received 11 June 2018 Revised 30 March 2019 Accepted 5 April 2019

Check for updates

(c) Author(s) (or their employer(s)) 2019. Re-use permitted under CC BY-NC. No commercial re-use. See rights and permissions. Published by BMJ.

${ }^{1}$ Institute of Public Health, University of Cambridge, Cambridge, UK

${ }^{2}$ Department of Public Health and Primary Care, University of Cambridge, Cambridge, UK ${ }^{3}$ Division of Psychiatry and Applied Psychology, University of Nottingham, Nottingham, UK

Correspondence to MS. Hanyuying Wang; hw448@medschl.cam.ac.uk

\section{ABSTRACT}

Objectives The present study aimed to examine the impact of loneliness on health and social care service use in the oldest old over a 7-year follow-up.

Design Prospective study.

Setting UK population-based cohort.

Participants 713 people aged 80 years or older were interviewed at wave 3 of the Cambridge City over-75s Cohort Study. Of these, 665 provided data on loneliness. During 7 years' follow-up, 480 participants left the study, of which 389 due to death. 162 still in the study answered the loneliness question.

Main outcome measure Use of health and social care services, assessed at each wave from wave 3 to wave 5 . Results At wave 3, of 665 participants who had data on Ioneliness, about $60 \%$ did not feel lonely, $16 \%$ felt slightly lonely and $25 \%$ felt lonely. Being slightly lonely at wave 3 was associated with a shorter time since last seeing a general practitioner ( $\beta=-0.5,95 \% \mathrm{Cl}$ : -0.8 to -0.2 ); when examining the association between time-varying Ioneliness and health and social care usage, being lonely was associated with three times greater likelihood of having contact with community nurses and using meals on wheels services (community nurse contact: incidence rate ratio $(\mathrm{IRR})=3.4,95 \% \mathrm{Cl}: 1.4$ to 8.7 ; meals on wheels service use: IRR=2.5, 95\% Cl: 1.1 to 5.6 ). No associations between loneliness and other health and social care services use were found.

Conclusion Loneliness was a significant risk factor for certain types of health and social care utilisations, independently of participants' health conditions, in the oldest old. Study findings have several implications, including the need for awareness-raising and prevention of loneliness to be priorities for public health policy and practice.

\section{INTRODUCTION}

Loneliness is an unpleasant feeling resulting from the mismatch between individuals' obtained social relationships and desired ones. It is commonly experienced by older people. Previous studies have reported that at any given time, about one quarter of individuals aged 65-79 reported feeling lonely, and
Strengths and limitations of this study

- Study participants were from one of the longest-run prospective cohort studies of the very old; a wide range of important confounders were adjusted for.

- Loneliness and health and social care utilisation were measured repeatedly during follow-up, so associations between time-varying loneliness and health and social care usage can be examined.

- Dropout and missing data were adjusted for by using inverse probability weighting.

- Findings from the current study might not generalise to all older populations because the Cambridge City over-75s Cohort Study recruited men and women living in only one city.

the percentage feeling loneliness increased to about $40 \%$ among individuals aged 80 and over. $^{1}$ There have been consistent reports both from longitudinal and cross-sectional studies on the association of loneliness with mental health, ${ }^{2}$ cognitive decline, ${ }^{3}{ }^{4}$ poor physical health ${ }^{5-7}$ and mortality. ${ }^{89}$ Those on mental health have been consistent across age groups studied.

Because of the strong relationships between loneliness and health outcomes, and the associations between adverse health and use of health and social services, there has been much interest in exploring the role of loneliness as an independent risk factor for health service and social care utilisation. However, findings from previous studies have been inconsistent. Using data from the Health and Retirement Study, researchers investigated whether loneliness was related to increased frequency of physician visits and hospital admission over a 4-year follow-up, and found that loneliness was significantly associated with physician visits but not hospital admission. ${ }^{10}$ However, a longitudinal study following up Canadian community-dwelling elders for 2.5 


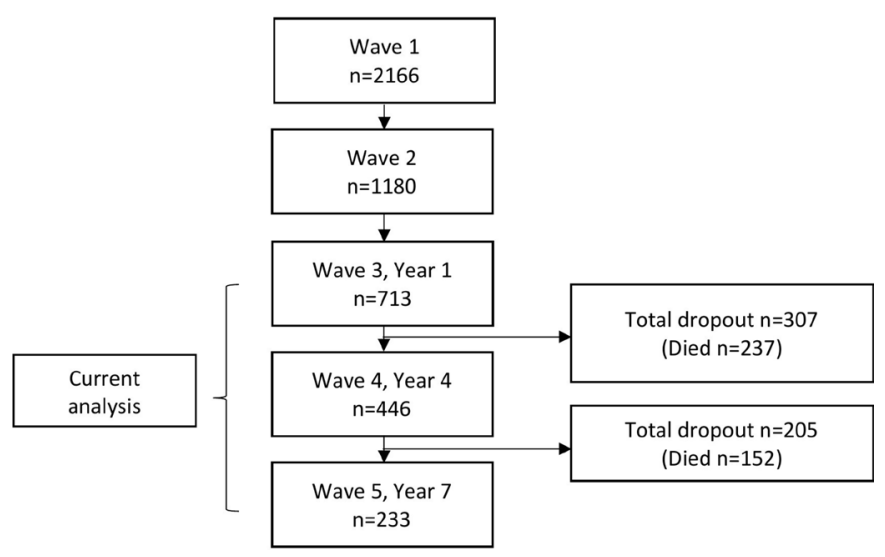

Figure 1 Overview of participation for current analysis.

years did not find any associations between loneliness and physician visits or hospitalisation. ${ }^{11}$ The heterogeneity in existing evidence is likely to be due to the differences in study sample, selection of covariates, length of follow-up time and the measures of loneliness. On the other hand, most studies focused on the general older population (aged 65 and over) with the oldest old (aged 80 and over) under-represented. Compared with the young old, the oldest old are at greater risk of losing family members and friends, experiencing physical or mental health decline, and therefore, are more vulnerable to changes in both loneliness and health, and consequently, their demand for health and social care services is greater. Moreover, to the best of our knowledge, only one longitudinal study examined the impact of loneliness on health and social care service use by using repeated assessments (loneliness was measured at two time points in that study) over time. ${ }^{10}$ However, with only two measures, researchers were not able to capture the fluctuating nature of loneliness; ${ }^{12-14}$ therefore, the complicated association between time-varying loneliness and health and social care utilisation could not be examined.

The current study aims to address two main questions. First, whether loneliness at baseline is associated with health and social care service use, and second, when loneliness was assessed at different times, whether there are relationships between time-varying loneliness and health and social care service use.

\section{METHOD}

\section{Study sample}

Participants were from wave 3 to wave 5 of the Cambridge City over-75s Cohort Study (CC75C), a population-based prospective cohort study of individuals aged 75 or older. The detailed description of this study can be found elsewhere. ${ }^{15}$ Briefly, in 1985, 2610 men and women aged 75 and over from geographically and socially representative general practices (GP) in Cambridge were recruited with a high response rate (95\% in six of the seven GP), of whom 2166 were at the initial wave of this study (444 were excluded due to different recruitment or participation in a concurrent intervention study). This group of individuals was then surveyed by trained lay interviewers using a similar questionnaire every 3 or 4 years, and in total, 10 waves of data have been collected. Written informed consent was obtained from all participants (or from their proxy informants for those who were frail). Patient and public involvement was not considered in the early 1980s at the design stage of the cohort study which collected the data in these analyses. Participants and their families were kept informed of study findings with regular newsletters. Figure 1 describes the overview of participation for current analysis.

\section{Patient and public involvement}

Patient and public involvement was not considered in the early 1980s at the design stage of the cohort study which collected the data in these analyses. Participants and their families were kept informed of study findings with regular newsletters.

\section{Measures}

Health and social care utilisation

The health and social care utilisation included in this study consisted of community service contacts, hospital visits and GP visits. The community service contact comprised the number of self-reported contacts with a home help, community nurse, meals on wheels or day centre in the past week. For each service, more than six contacts a week were coded as six. Hospital visits was assessed by asking participants how many times they had been in hospital in the past year, coded 0,1 or 2 with this maximum score reflecting 2 or more, due to the small frequency of more frequent visits. As an indicator of frequency of GP visits, participants were asked how long it had been since they last saw a GP; answers were recorded in months up to a maximum of 98 . In analyses, community service contact and hospital visit responses were treated as count variables, and time since last GP visit was treated as a continuous variable.

\section{Loneliness}

At each wave, loneliness was assessed by a single question 'Do you feel lonely?', with response options 'not at all lonely', 'slightly lonely', 'lonely' and 'very lonely'. In analyses, due to the small number of participants who reported feeling lonely or very lonely, these two categories were then combined as one category: 'lonely'. Therefore, loneliness was divided into three levels here: 'not lonely' (indicates 'not at all lonely'), 'slightly lonely' and 'lonely' (indicates 'lonely' and 'very lonely'). The singleitem scale was used widely in European studies, and it has been reported that it was adopted well by the older population. $^{16}$

\section{Covariates}

The covariates included in analyses were demographics and variables associated with loneliness and health outcomes. They were age (80-84, 85-89 and 90+), sex (men as the reference), physical impairments (measured 
through a series of self-reported or proxy-reported conditions, including poor vision, poor hearing, arthritis/ rheumatism, back pain, chest pain, shortness of breath, marked weakness in arms or leg, unsteady on feet, tendency to fall, trouble with nerves and others; the total score was the sum of score for each condition and categorised into low, moderate and severe levels based on $25 \%$, $50 \%$ and $75 \%$ percentiles), number of chronic diseases (included self-reported doctor-diagnosed angina, heart attack, circulation problems in legs, high blood pressure, chronic bronchitis, stroke, sudden weakness or difficulty with speech, memory or vision, sugar diabetes, thyroid problems, severe headaches or migraine and others; categorised into $0-2$ or $\geq 3$ conditions), depression (measured by a series of questions derived from the Cambridge Examination for Mental Disorders in the Elderly ${ }^{17}$ the total score ranged from 0 to 10 and depression was defined if score $\geq 6$ ), physical functioning (assessed by participants' responses to questions on activities of daily living (ADL), and categorised into no disability, instrumental ADL (IADL) disability only or disability in both basic ADLs and IADLs) ${ }^{18}$ and cognition (assessed by MiniMental Status Examination (MMSE), score ranged from 0 to 30$)$. All covariates were measured at wave 3 .

\section{Statistical analysis}

The current analyses included participants who had provided data on loneliness at wave 3. Loneliness non-response at wave 3 was adjusted by inverse probability weighting. The calculation was modelled on variables associated with loneliness missingness. The characteristics of the sample were described according to their wave 3 loneliness level after adjusting for non-response.

To examine the association between loneliness and health and social care utilisation over a 7-year follow-up, generalised estimating equations (GEE) with independent variance matrix and negative binomial family were fitted to model count outcomes, and GEE with independent variance matrix with Gamma family was used to model the continuous outcome. The use of GEE with independent variance matrix is expected to ensure that the target for inference is based on the mortal cohort (living population at each wave). ${ }^{19} 20$ The use of negative binomial modelling for count responses can help with overdispersion control in the data. ${ }^{21}$ The choice of Gamma family for modelling the continuous outcome was because the distribution of continuous variable 'time since last visiting a GP' was not normally distributed and fits into one of the Gamma distribution shapes, a Gamma distribution was therefore assumed. Two types of associations were tested. First, the association between baseline loneliness (measured at wave 3) and health and social care usage (repeated measurements at waves 3, 4 and 5) was explored, and then the association between loneliness as a time-varying predictor (measured at waves 3,4 and 5) and health and social care usage was investigated (again, repeated measurements at waves 3, 4 and 5) (figure 2). In both analyses, time was entered (ie, $t=1,2,3)$ to reflect
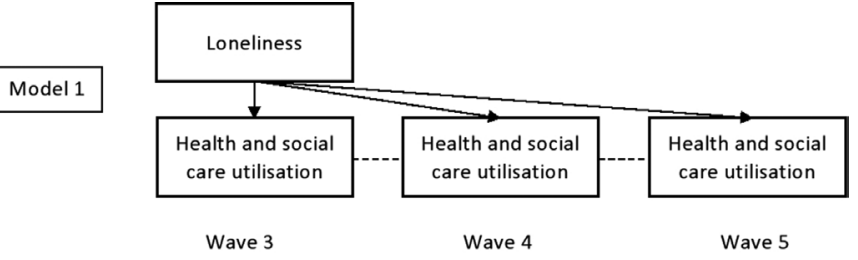

Model 2

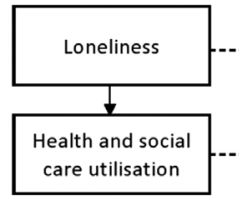

Wave 3

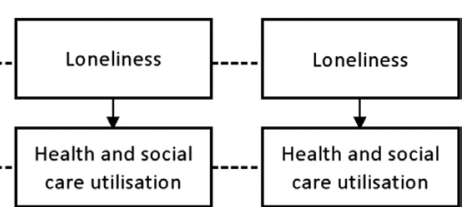

Wave 4

Wave 5
Figure 2 Overview of statistical models.

the order of the three repeated measurements. Both analyses were adjusted for covaries.

To adjust for dropout during follow-up, the inverse probability weighting was calculated based on probability of staying in the study on the condition of responding to the previous wave and being alive at the current wave. ${ }^{192-24}$ As participants in this study were followed up from wave three onwards, cross-sectional weight adjusting for dropout before wave three was calculated. Taken together, a final weight was calculated by multiplying wave 3 cross-sectional weight, weight adjusting for loneliness non-response at wave 3 and longitudinal weight, and implemented in longitudinal analyses.

Because several covariates included in the analyses were health-related, such as physical impairment, physical functioning and number of chronic diseases; despite that they were collected in distinctive ways, a sensitivity analysis was performed to test the impact of loneliness on health and social service use adjusting only for physical functioning.

All analyses were implemented in Stata V.13.1. A p-value $<0.05$ was considered statistically significant.

\section{RESULTS}

During the 7-year follow-up, $\mathrm{n}=480 / 713(67 \%)$ participants dropped out from study, and $n=389 / 480(81 \%)$ dropped out due to mortality (figure 1 ). At wave $3, n=393$ participants reported that they were not lonely and, of those reporting any degree of loneliness, $n=107$ and $\mathrm{n}=165$ said they felt 'slightly lonely' and 'lonely', respectively (table 1). For 48/713 (7\%) participants with no valid response to the loneliness question at wave $3, \mathrm{n}=35$ were proxy informant interviews. Over half of participants were aged at least 85 years old, most were women, had a moderate level of physical impairment, had less than three chronic diseases, and were not depressed. About $40 \%$ of participants did not have any disabilities, while approximately $35 \%$ suffered from both IADL and ADL disabilities. The average MMSE score was 23. 
Table 1 Participants' characteristics at wave 3

\begin{tabular}{|c|c|c|}
\hline & $\begin{array}{l}\text { No of } \\
\text { participants }\end{array}$ & $\begin{array}{l}\% \text { of } \\
\text { participants }\end{array}$ \\
\hline Characteristics & 665 & 100 \\
\hline \multicolumn{3}{|l|}{ Loneliness } \\
\hline Not lonely & 393 & 59 \\
\hline Slightly lonely & 107 & 16 \\
\hline Lonely & 165 & 25 \\
\hline \multicolumn{3}{|l|}{ Age (years) } \\
\hline $80-84$ & 304 & 46 \\
\hline 85-89 & 267 & 40 \\
\hline $90+$ & 94 & 14 \\
\hline \multicolumn{3}{|l|}{ Sex } \\
\hline Men & 207 & 31 \\
\hline Women & 458 & 69 \\
\hline \multicolumn{3}{|l|}{ Physical impairment } \\
\hline Low & 227 & 35 \\
\hline Moderate & 292 & 45 \\
\hline High & 130 & 20 \\
\hline \multicolumn{3}{|l|}{ Number of chronic diseases } \\
\hline $0-2$ & 409 & 64 \\
\hline$\geq 3$ & 228 & 36 \\
\hline \multicolumn{3}{|l|}{ Depression } \\
\hline No & 538 & 87 \\
\hline Yes & 78 & 13 \\
\hline \multicolumn{3}{|l|}{ Physical functioning } \\
\hline No disability & 249 & 38 \\
\hline IADL disability only & 176 & 27 \\
\hline IADL and ADL disability & 231 & 35 \\
\hline Cognition* & $23(6) \dagger$ & - \\
\hline
\end{tabular}

${ }^{*}$ Cognition was measured as a continuous variable ranging from 1 to 30 with higher score indicating better cognition.

$\dagger$ Mean \pm SD. Because of the missing data, the sum of column data for certain variables may not equal to 665 .

$A D L$, activities of daily living; IADL, instrumental ADL.

Table 2 shows the weighted percentage of participants in each category by loneliness level measured at wave 3 . The prevalence of feeling lonely was high among women and individuals who had a moderate to high level of physical impairment, were depressed and had disabilities in IADL and ADL (table 2).

In terms of associations between baseline loneliness and health and social care utilisation, the only significant association was that feeling slightly lonely was positively associated with GP visits after adjusting for demographic characteristics and health problems (table 3). Neither feeling lonely nor feeling slightly lonely were found to be related to home help use, community nurse contacts, meals on wheels service use, day centre or hospital visits. Results also indicated that moderate and high levels of
Table 2 The distribution of baseline characteristics by Ioneliness level (weight ${ }^{\star}$ applied)

\begin{tabular}{|c|c|c|c|c|}
\hline & $\begin{array}{l}\text { Not } \\
\text { lonely }\end{array}$ & $\begin{array}{l}\text { Slightly } \\
\text { lonely } \\
\end{array}$ & $\begin{array}{l}\text { Lonely } \\
25 \%\end{array}$ & \\
\hline Characteristics & $59 \%$ & $16 \%$ & $25 \%$ & P value \\
\hline \multicolumn{5}{|l|}{ Age (years) } \\
\hline $80-84$ & $63 \%$ & $16 \%$ & $21 \%$ & 0.26 \\
\hline $85-89$ & $55 \%$ & $18 \%$ & $27 \%$ & \\
\hline $90+$ & $57 \%$ & $13 \%$ & $30 \%$ & \\
\hline \multicolumn{5}{|l|}{ Sex } \\
\hline Men & $71 \%$ & $12 \%$ & $17 \%$ & $<0.001$ \\
\hline Women & $53 \%$ & $18 \%$ & $29 \%$ & \\
\hline \multicolumn{5}{|l|}{ Physical impairment } \\
\hline Low & $76 \%$ & $12 \%$ & $12 \%$ & $<0.001$ \\
\hline Moderate & $59 \%$ & $15 \%$ & $26 \%$ & \\
\hline High & $37 \%$ & $23 \%$ & $40 \%$ & \\
\hline \multicolumn{5}{|c|}{ Number of chronic diseases } \\
\hline $0-2$ & $63 \%$ & $16 \%$ & $21 \%$ & 0.13 \\
\hline$\geq 3$ & $56 \%$ & $16 \%$ & $28 \%$ & \\
\hline \multicolumn{5}{|l|}{ Depression } \\
\hline No & $65 \%$ & $15 \%$ & $20 \%$ & $<0.001$ \\
\hline Yes & $25 \%$ & $24 \%$ & $51 \%$ & \\
\hline \multicolumn{5}{|l|}{ Physical functioning } \\
\hline No disability & $59 \%$ & $18 \%$ & $23 \%$ & $<0.05$ \\
\hline IADL disability only & $70 \%$ & $12 \%$ & $18 \%$ & \\
\hline $\begin{array}{l}\text { IADL and ADL } \\
\text { disabilities }\end{array}$ & $54 \%$ & $17 \%$ & $29 \%$ & \\
\hline \multicolumn{5}{|l|}{ Cognition (mean $\pm S D$ ) } \\
\hline MMSE & $22(6)$ & $22(6)$ & $21(7)$ & 0.7 \\
\hline
\end{tabular}

*Weight: the product of wave 3 cross-sectional weight and weight adjusted for non-response at wave 3 .

ADL, activities of daily living; IADL, instrumental ADL; MMSE, Mini-Mental Status Examination.

physical impairment were significantly associated with home help use and with hospital visits. Having three or more chronic diseases was associated with community nurse contacts. Having disabilities in both IADL and ADL was related to increased frequency of day centre visits. On the other hand, depression was significantly and negatively associated with day centre visits. However, being depressed was associated with shorter time since last seeing a GP. Moreover, being female and having at least three chronic diseases was also associated with GP visits.

Table 4 presents the results of time-varying loneliness for health and social care usage. Individuals who felt lonely were three times more likely to contact the community nurse and use the meals on wheels service than non-lonely individuals, respectively. The other variables that were significantly associated with health and social care utilisation were similar to those in the analyses exploring the association between baseline loneliness and health and social care usage, except that the significance 
Table 3 Associations between baseline loneliness and health and social care utilisation

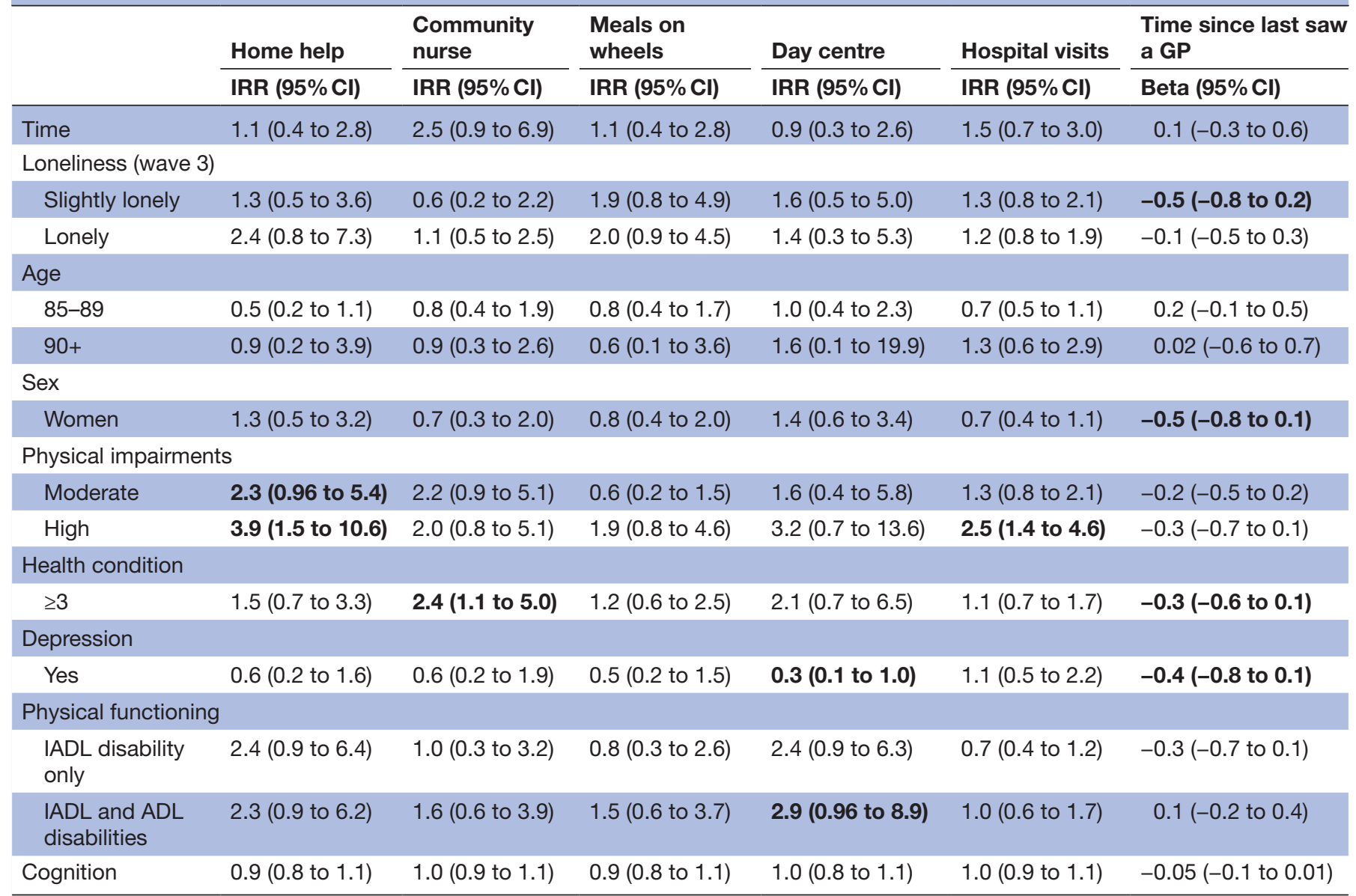

Reference groups: not lonely, 80-84 years old, men, no physical impairments, 0-2 chronic diseases, not depressed and not disabled. Bold values indicate $95 \%$ confidence intervals.

$A D L$, activities of daily living; IADL, instrumental ADL; IRR, incidence rate ratio.

of the associations between depression, disabilities in IADL and ADL and day centre visits disappeared; instead, the high level of physical impairment was found to be significantly related to day centre visits.

The effect sizes of loneliness, either base-line loneliness or time-varying loneliness, on health and social care service use in sensitivity analyses were similar with that from the main analyses (Supplementary information).

\section{DISCUSSION}

Results from this study indicate that loneliness is a significant risk factor for certain types of health and social care services among the oldest old regardless of health problems. In particular, feeling slightly lonely at baseline was associated with a shorter time since last GP visiting; when modelling the association between repeated measures of loneliness and health and social care usage, feeling lonely was found to be significantly associated with increased contacts with the community nurse and use of a meals on wheels service. The results from the sensitivity analysis did not differ from the presented results substantively, generally supporting the conclusions made based on the current analysis.

The finding of loneliness and its association with GP visits is consistent with the finding from a previous UK population-based study, though there are slight differences between the two studies. In our study, compared with non-lonely individuals, we found that those who felt slightly lonely had a shorter time interval since they last visited their GP; in their study, they found that individuals who felt lonely tended to visit GPs about twice as often as individuals who were not lonely. ${ }^{25}$ The explanations for the link between loneliness and frequent GP visits might include that GPs are the first point of call for multiple care needs, and more importantly, the GP healthcare system is intended to allow GPs to build a long-term relationship with their patients. GPs therefore may be familiar with their patients' health conditions and even emotional changes, and consequently trust can be built within this relationship. Indeed, Ellaway and colleagues explained that older people who felt lonely and did not have family members or friends around them tended to regard their GPs as their confidants. ${ }^{25}$ Similarly, data 
Table 4 Association between time-varying loneliness and health and social care utilisation

\begin{tabular}{|c|c|c|c|c|c|c|}
\hline & Home help & $\begin{array}{l}\text { Community } \\
\text { nurse }\end{array}$ & $\begin{array}{l}\text { Meals on } \\
\text { wheels }\end{array}$ & Day centre & Hospital visits & $\begin{array}{l}\text { Time since last saw } \\
\text { a GP }\end{array}$ \\
\hline & IRR (95\% Cl) & IRR (95\% CI) & IRR (95\% CI) & IRR (95\% CI) & IRR $(95 \% \mathrm{CI})$ & Beta $(95 \% \mathrm{Cl})$ \\
\hline Time & $1.0(0.4$ to 2.5$)$ & 2.3 (0.9 to 5.8$)$ & $1.0(0.4$ to 2.6$)$ & $1.4(0.4$ to 4.9$)$ & $1.3(0.7$ to 2.6$)$ & $0.1(-0.3$ to 0.5$)$ \\
\hline \multicolumn{7}{|l|}{ Loneliness } \\
\hline Slightly lonely & 1.2 (0.5 to 2.9$)$ & 0.8 (0.3 to 2.6$)$ & $1.6(0.6$ to 3.8$)$ & $1.7(0.5$ to 5.5$)$ & $1.4(0.9$ to 2.1$)$ & $0.3(-0.6$ to 0.1$)$ \\
\hline Lonely & 2.0 (0.8 to 4.9$)$ & 3.4 (1.4 to 8.7 ) & $2.5(1.1$ to 5.6$)$ & $1.4(0.4$ to 5.3$)$ & 1.5 (0.9 to 2.4$)$ & $0.2(-0.5$ to 0.1$)$ \\
\hline \multicolumn{7}{|l|}{ Age } \\
\hline $85-89$ & 0.5 (0.2 to 1.1$)$ & 0.8 (0.3 to 1.9$)$ & $1.0(0.5$ to 2.0$)$ & $1.0(0.4$ to 2.5$)$ & 0.7 (0.5 to 1.2$)$ & $0.2(-0.1$ to 0.5$)$ \\
\hline $90+$ & 0.9 (0.2 to 4.4$)$ & 1.3 (0.4 to 4.7$)$ & $0.6(0.1$ to 5.9$)$ & $4.2(0.3$ to 51.7$)$ & 1.0 (0.4 to 2.7 ) & $0.1(-0.6$ to 0.7$)$ \\
\hline \multicolumn{7}{|l|}{ Sex } \\
\hline Women & $1.2(0.5$ to 3.1$)$ & $0.5(0.2$ to 1.5$)$ & 0.8 (0.3 to 1.9$)$ & $1.4(0.5$ to 4.0$)$ & 0.6 (0.4 to 1.002$)$ & $0.5(-0.9$ to 0.2$)$ \\
\hline \multicolumn{7}{|c|}{ Physical impairments } \\
\hline Moderate & 2.3 (0.9 to 5.7 ) & 1.9 (0.8 to 4.5$)$ & 0.7 (0.2 to 2.0$)$ & 4.0 (0.7 to 23.4$)$ & 1.3 (0.8 to 2.1$)$ & $0.1(-0.5$ to 0.2$)$ \\
\hline High & 4.1 (1.6 to 10.8$)$ & 1.4 (0.4 to 4.5$)$ & 1.9 (0.7 to 5.3$)$ & 7.6 (1.2 to 48.7$)$ & 2.3 (1.2 to 4.4$)$ & $0.3(-0.7$ to 0.1$)$ \\
\hline \multicolumn{7}{|l|}{ Health condition } \\
\hline$\geq 3$ & 1.5 (0.7 to 3.3$)$ & 2.6 (1.2 to 5.5$)$ & 1.2 (0.6 to 2.6$)$ & 2.3 (0.6 to 8.7 ) & $1.2(0.8$ to 1.9$)$ & $0.3(-0.6$ to 0.1$)$ \\
\hline \multicolumn{7}{|l|}{ Depression } \\
\hline Yes & $0.6(0.2$ to 1.6$)$ & 0.5 (0.2 to 1.5$)$ & 0.5 (0.2 to 1.7$)$ & $0.3(0.1$ to 1.1$)$ & $1.1(0.5$ to 2.1$)$ & $0.4(-0.8$ to 0.03$)$ \\
\hline \multicolumn{7}{|c|}{ Physical functioning } \\
\hline $\begin{array}{l}\text { IADL disability } \\
\text { only }\end{array}$ & 2.1 (0.8 to 5.6$)$ & 0.9 (0.3 to 2.7$)$ & 0.8 (0.2 to 2.6$)$ & 2.7 (0.9 to 8.5$)$ & 0.7 (0.4 to 1.3$)$ & $0.3(-0.7$ to 0.1$)$ \\
\hline $\begin{array}{l}\text { IADL and ADL } \\
\text { disabilities }\end{array}$ & 2.3 (0.8 to 6.3 ) & 1.0 (0.4 to 2.5$)$ & 1.5 (0.5 to 4.5$)$ & 2.1 (0.7 to 6.7 ) & $1.0(0.6$ to 1.7$)$ & $0.2(-0.1$ to 0.5$)$ \\
\hline Cognition & 0.9 (0.8 to 1.0$)$ & 0.9 (0.8 to 1.0$)$ & $0.9(0.8$ to 1.1$)$ & 1.1 (0.9 to 1.2$)$ & $1.0(0.9$ to 1.1$)$ & $0.05(-0.1$ to 0.0003$)$ \\
\hline
\end{tabular}

Reference groups: not lonely, 80-84 years old, men, no physical impairments, 0-2 chronic diseases, not depressed and not disabled. Bold values indicate $95 \%$ confidence intervals.

$A D L$, activities of daily living; IADL, instrumental ADL; IRR, incidence rate ratio .

from the 'Campaign to End Loneliness' suggest that more than $75 \%$ of GPs and one in 10 hospital doctors reported seeing about $1-5$ or 1-6 lonely people in a day. ${ }^{26}$ These findings imply that numerous lonely individuals are aware of their loneliness and have self-motivations to alleviate loneliness. Seeking advice from trusted GPs may give them a sense of hope and safety. Findings also highlight the importance of emotional support (eg, having confidants) in the experience of loneliness.

To the best of our knowledge, this is the first time the associations between loneliness and community nurse contacts and use of a meals on wheels service have been studied. Although potentially indicating that these types of service use are markers for levels of poor health and disability associated with greater loneliness, the associations remained after controlling for numbers of health conditions. The independent significance of these associations could imply that similar with GPs, community nurses or meals on wheels service providers may have a hidden role in providing social interactions. For example, in a fixed randomised control study investigating the role of home-delivered meals programme on 626 American community-dwelling seniors' feelings of loneliness, researchers reported that compared with control groups (ie, individuals who received meal delivery once a week and individuals remained on meal delivery waiting list), those who received their meals delivery on a daily basis experienced decreases in their loneliness, and the reduction was explained as the meal-delivery services indirectly provided more opportunities to elders for social interactions. ${ }^{27}$

This study has several strengths. The use of data from one of the longest-run prospective cohort studies of the very old allows us to measure loneliness and outcome variables at different time points; by using the repeated measurements, we can therefore examine the association between loneliness and health and social care utilisation more thoroughly. Moreover, CC75C collected data on different types of health and social care services, which enables us to investigate the impact of loneliness on health and social care utilisation in a broader way than previous studies did. Furthermore, the use of weights can minimise the effect of non-response to the findings and reduce bias due to dropout. ${ }^{20}$

However, caution should be taken when interpreting the findings. The use of self-reported health service and 
social care utilisation may introduce recall bias. However, it is unlikely to have effects on our findings as for most interviewed participants, their proxy informants were also interviewed, and answers from both were compared and the most reliable answers (ie, if answers were different, then proxy informants' answers were selected for participants who had cognitive problems) to minimise the differences. Responses about health and social care service use were coded with maximum values, without recording the true maximum. It is possible that some participants are heavy users of services, resulting in higher service use than measured here. It is possible that this led to a loss of ability to identify relationships for heavy users of services, and no sensitivity analyses are possible to test this. However, for each type of health and social service, the largest proportion of participants who were in the maximum category was less than 6\%. Therefore, results from the current study are unlikely to be influenced by the extreme values of service use. Additionally, the use of a single-item scale to assess loneliness may underestimate the true prevalence of loneliness as participants might be concerned about social stigma, but it has been reported that single-item scales have advantages in implementation in large studies and have good reliability among older people. ${ }^{16}$ Another consideration is that, as in previous studies,${ }^{10}$ we included disability as one of the covariates, and it was determined by whether participants needed help from family, friends or neighbours for performing at least one of their daily activities, such as cooking or doing housework. This type of help can be regarded as informal care; therefore, it is possible that participants who can obtain informal care may use fewer community services. Medication use may also serve as a confounder in this analysis, as individuals who are taking prescribed medications may need to visit their GPs more regularly. However, because of the unavailability of relevant data, we were unable to adjust for this variable. Although this might dilute the association between loneliness and healthcare utilisation, it was unlikely to change the direction of the association.

This finding has implications for public health and practice. As noted earlier, lonely individuals visit their GPs more frequently than non-lonely individuals. They expect emotional supports and professional advice from their GPs to alleviate feelings of loneliness. However, from GPs' point of view, they are burdened with lack of therapeutic options. This might be due to the fact that feeling lonely reflects individuals' personal experience; therefore, the trigger for loneliness varies between individuals. Moreover, the coping skills differ from individuals. In addition, GPs need to deal with time issues, for example, lack of time. Taken together, the limited options to support people affected with loneliness and lack of time make it difficult for GPs to help with lonely patients. ${ }^{28}$ This raises an urgent need for developing professional service that specifically target on loneliness, so that GPs can refer their lonely patients to appropriate help. Indeed, in a recent programme 'The town with a plan to end loneliness' aired by the BBC, a programme presenter pointed out that the medical centre not only is responsible for giving medical advice, but also should listen to patients' non-medical needs and connect them to people who can help. ${ }^{29}$

In addition, the finding that loneliness was associated with increased use of community services, such as frequent nurse contacts and meals on wheels service usage, has implications on public policy. This implication may be more pronounced for public officials in developing countries. For example, China is also facing quickened population ageing. However, the traditional social welfare system cannot meet the care needs resulting from the rapidly increased number of older people. The government has just recognised the importance of community services and is prioritising fostering the development of community services. ${ }^{30}$ Interestingly, in spite of the differences in social and cultural contexts, the specific services that the Chinese government focuses on are day care, dining rooms or other centralised meal delivery services, echoing the community services in western countries. ${ }^{31}$ Although the public official has been long aware that chronic diseases, such as physical and cognitive impairments, are strong predictors for community care services, loneliness as a risk factor has been neglected. Findings from the current study add new evidence, that is, loneliness also contributes to the great needs for community care services to public. Despite the strong associations between loneliness and increased use of GP and community-based services, it is possible that lonely individuals have less knowledge about appropriate access to health and social care services or do not have the means to access them than non-lonely individuals. Given the robust link between loneliness and health outcomes reported in previous studies, individuals who are lonely may be at higher risk of health decline, and consequently are likely to have greater need of health services. However, in the current analysis, health conditions were adjusted for, implying that there might be other mechanisms underlying the association between loneliness and health and social care services usage. This again emphasises the importance of developing services that are sensitive to loneliness.

In conclusion, loneliness was found to be associated with frequent GP visits, community nurse contacts and meals on wheels service usage, independently of participants' health problems. As population ageing is happening across the world, it is urgent to realise the significance of loneliness on health service and social care demands. Moreover, evidence on interventions to prevent and reduce loneliness do not show promising results. ${ }^{32}$ Future research is required to examine risk factors for loneliness in order to develop effective interventions that target on loneliness alleviation.

Acknowledgements The authors gratefully acknowledge the contribution of previous investigators, past research team members and staff in collaborating general practices and care homes, as well as the study respondents, their families and friends without whose help none of this research would be possible. 
Contributors HW proposed the research idea and conducted the analysis, as well as drafted the manuscript. CB critically reviewed the draft of this manuscript and provided input into analysis. EZ, JF, TD and K-TK provided feedback. JF and TD edited versions of the manuscript. All authors agreed to the submitted version of the paper.

Funding The first author researcher received no specific grant from any funding agency in the public, commercial or not-for-profit sectors. We thank all the past CC75C sponsors for financial support spanning the decades since the Medical Research Council enabled the first follow-up survey (see study website for full list of project grants: http://www.cc75c.group.cam.ac.uk/background/grants/), most recently the Abbeyfield Research Foundation and the BMA Foundation for Medical Research Dawkins and Strutt Grant. CC75C was a member study of the National Institute for Health Research funded Collaboration for Leadership in Applied Health Research and Care for Cambridgeshire and Peterborough. No funder sponsor played any role in the study design; in the collection, analysis and interpretation of data; or in the writing of the report and the decision to submit the article for publication. All researchers were independent from funders.

Competing interests None declared.

Patient consent for publication Not required

Ethics approval The study is approved by the East of England-Cambridge Central Research Ethics Committee, approval number 05/ Q0108/308.

Provenance and peer review Not commissioned; externally peer reviewed. Data sharing statement № additional data are available.

Open access This is an open access article distributed in accordance with the Creative Commons Attribution Non Commercial (CC BY-NC 4.0) license, which permits others to distribute, remix, adapt, build upon this work non-commercially, and license their derivative works on different terms, provided the original work is properly cited, appropriate credit is given, any changes made indicated, and the use is non-commercial. See: http://creativecommons.org/licenses/by-nc/4.0/.

\section{REFERENCES}

1. Dykstra PA. Older adult loneliness: myths and realities. Eur J Ageing 2009;6:91-100.

2. Nolen-Hoeksema S, Ahrens C. Age differences and similarities in the correlates of depressive symptoms. Psychol Aging 2002;17:116-24.

3. O'Luanaigh $\mathrm{C}, \mathrm{O}^{\prime}$ Connell $\mathrm{H}$, Chin $\mathrm{AV}$, et al. Loneliness and cognition in older people: the Dublin Healthy Ageing study. Aging Ment Health 2012;16:347-52

4. Wilson RS, Krueger KR, Arnold SE, et al. Loneliness and risk of Alzheimer disease. Arch Gen Psychiatry 2007;64:234-40.

5. Hawkley LC, Thisted RA, Masi CM, et al. Loneliness predicts increased blood pressure: 5-year cross-lagged analyses in middleaged and older adults. Psychol Aging 2010;25:132-41.

6. Keysor JJ. Does late-life physical activity or exercise prevent or minimize disablement? A critical review of the scientific evidence. Am J Prev Med 2003;25:129-36.

7. Luo Y, Hawkley LC, Waite LJ, et al. Loneliness, health, and mortality in old age: a national longitudinal study. Soc Sci Med 2012;74:907-14.

8. Kurina LM, Knutson KL, Hawkley LC, et al. Loneliness is associated with sleep fragmentation in a communal society. Sleep 2011;34:1519-26.

9. Holt-Lunstad J, Smith TB, Baker M, et al. Loneliness and social isolation as risk factors for mortality: a meta-analytic review. Perspect Psychol Sci 2015;10:227-37.

10. Gerst-Emerson K, Jayawardhana J. Loneliness as a public health issue: the impact of loneliness on health care utilization among older adults. Am J Public Health 2015;105:1013-9.
11. Newall N, McArthur J, Menec VH. A longitudinal examination of social participation, loneliness, and use of physician and hospital services. J Aging Health 2015;27:500-18.

12. Wenger GC, Burholt V. Changes in levels of social isolation and loneliness among older people in a rural area: a twenty-year longitudinal study. Canadian Journal on Aging / La Revue canadienne du vieillissement 2004;23:115-27.

13. Victor CR, Bowling A. A longitudinal analysis of loneliness among older people in Great Britain. J Psychol 2012;146:313-31.

14. Brittain K, Kingston A, Davies K, et al. An investigation into the patterns of loneliness and loss in the oldest old - Newcastle 85+ Study. Ageing Soc 2017;37:39-62.

15. Fleming J, Zhao E, O'Connor DW, et al. Cohort profile: the Cambridge City over-75s Cohort (CC75C). Int J Epidemiol 2007;36:40-6.

16. Victor C, Grenade L, Boldy D. Measuring loneliness in later life: a comparison of differing measures. Rev Clin Gerontol 2005;15:63-70.

17. Roth M, Tym E, Mountjoy CQ, et al. CAMDEX. A standardised instrument for the diagnosis of mental disorder in the elderly with special reference to the early detection of dementia. $\mathrm{Br} J$ Psychiatry 1986;149:698-709.

18. Lawton MP, Brody EM. Assessment of older people: selfmaintaining and instrumental activities of daily living. Gerontologist 1969;9:179-86.

19. Kurland BF, Heagerty PJ. Directly parameterized regression conditioning on being alive: analysis of longitudinal data truncated by deaths. Biostatistics 2005;6:241-58.

20. Jones M, Mishra GD, Dobson A. Analytical results in longitudinal studies depended on target of inference and assumed mechanism of attrition. J Clin Epidemiol 2015;68:1165-75.

21. Karazsia BT, van Dulmen $\mathrm{MH}$. Regression models for count data: illustrations using longitudinal predictors of childhood injury. J Pediatr Psychol 2008;33:1076-84.

22. Robins JM, Rotnitzky A, Zhao LP. Analysis of semiparametric regression models for repeated outcomes in the presence of missing data. J Am Stat Assoc 1995;90:106-21.

23. Dufouil C, Brayne C, Clayton D. Analysis of longitudinal studies with death and drop-out: a case study. Stat Med 2004;23:2215-26.

24. Kurland BF, Johnson LL, Egleston BL, et al. Longitudinal Data with Follow-up Truncated by Death: Match the Analysis Method to Research Aims. Stat Sci 2009;24:211-22.

25. Ellaway A, Wood S, Macintyre S. Someone to talk to? The role of loneliness as a factor in the frequency of GP consultations. $\mathrm{Br} J$ Gen Pract 1999;49:363-7.

26. Cooper $\mathrm{C}$. The Campaign to End Loneliness Surveyed more than 1,000 family doctors. Independent. 2013 https://www.independent. co.uk/life-style/health-and-families/health-news/charity-claimsloneliness-is-the-reason-one-in-10-visit-their-gp-8940392.html (accessed 5 May 2018).

27. Thomas KS, Akobundu U, Dosa D. More Than A Meal? A Randomized Control Trial Comparing the Effects of Home-Delivered Meals Programs on Participants' Feelings of Loneliness. J Gerontol B Psychol Sci Soc Sci 2016;71:1049-58.

28. van der Zwet J, Koelewijn-van Loon MS, van den Akker M. Lonely patients in general practice: a call for revealing GPs' emotions? A qualitative study. Fam Pract 2009;26:501-9.

29. BBC World Hacks. The town with a plan to end loneliness, 2018.

30. Zhou J, Walker A. The need for community care among older people in China. Ageing Soc 2016;36:1312-32.

31. Tian $\mathrm{Q}$. Community care for the elderly: comparative study based on welfare pluralism. Doctoral dissertation 2010.

32. Sander R. Preventing social isolation and loneliness among older people: a systematic review of health promotion interventions. Nurs Older People 2005;17:40-67. 